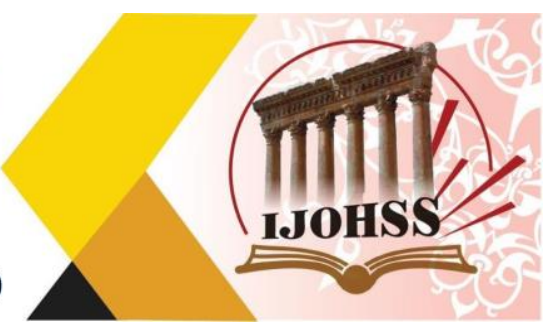

\title{
اثر طريقة المحو التدريجي في حفظ التصوص الادبية لتلاميذ الصف الرابع الابتدائي
}

\author{
م.د. قاسم عبد الامير حمبدي \\ المديرية العامة لتربية محافظة كربلاء الامير حمبل

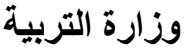

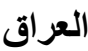 \\ Bghdad2024@gmail.com
}

\author{
م.د. علاء شيال فاخر محمد \\ قسم الترجمة ـ كلية الآداب \\ الجامعة العراقية الجية \\ العراق \\ bbnn801bn@gmail.com
}

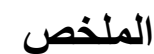

هدف البحث إلى التعرف على اثر طريقة المحو التدريجي في حفظ النصوص الادبيـة لتلاميذ الصف الرابع

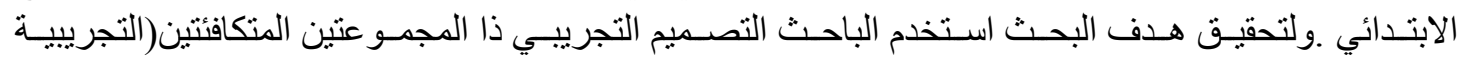

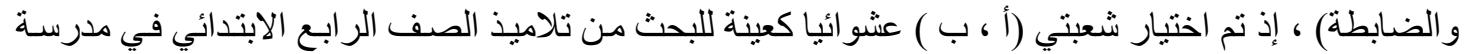

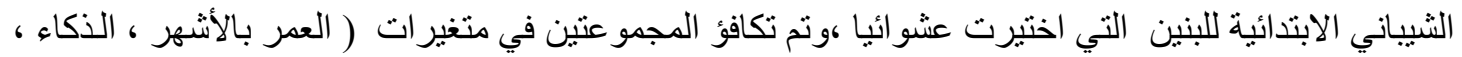

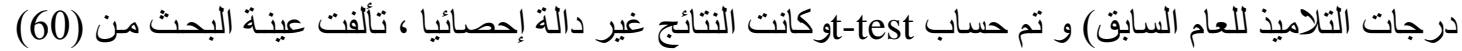

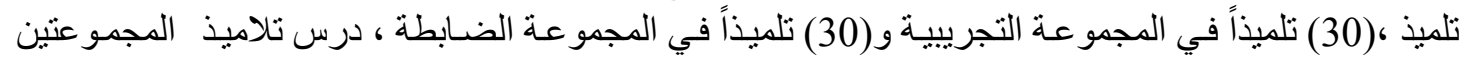

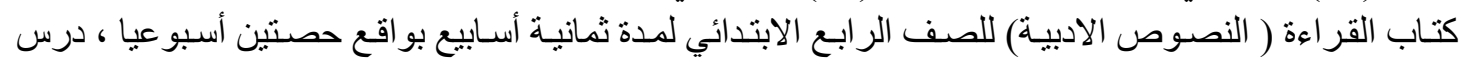

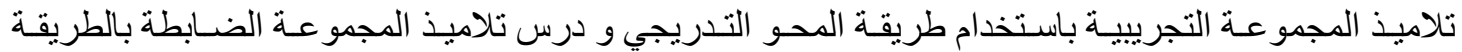

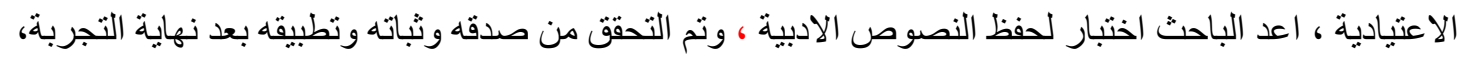

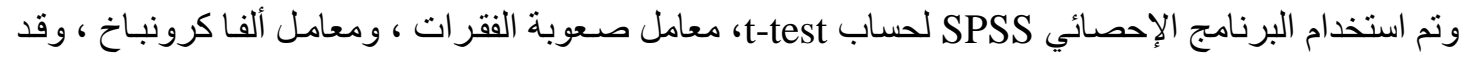

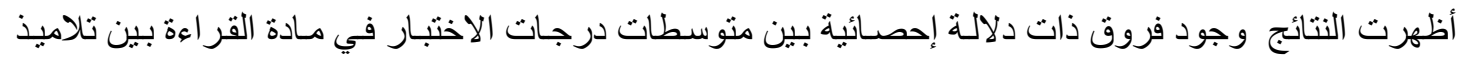

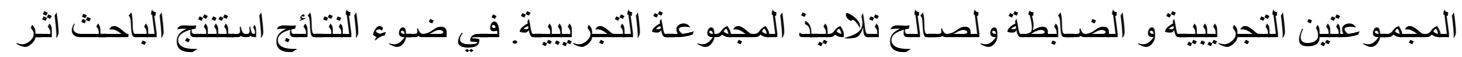

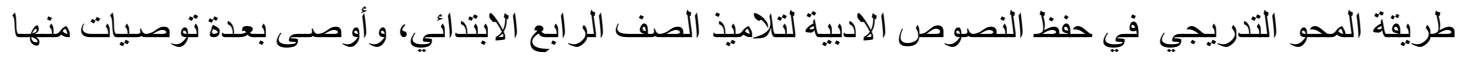

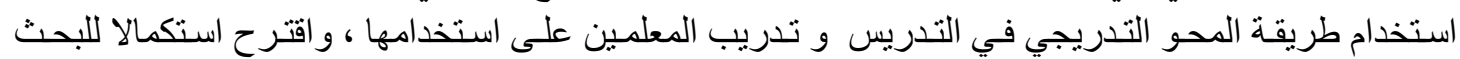
الحالي استخدام الطريقة في مر احل در اسية أخرى و مع متغير ات أخرى لخدئ

الكلمات المفتاحية: المحو التدريجي، حفظ النصوص الادبية، الرابع الابتدائي. 


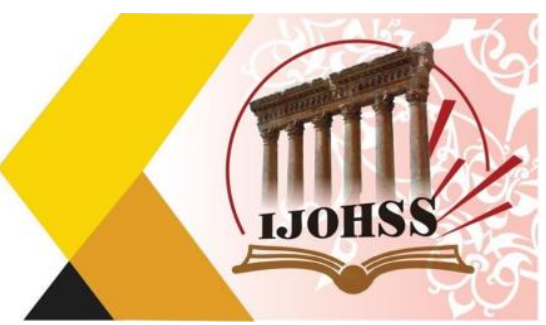

\title{
The Effect of the Gradual Erasure Method on Memorizing Literary Texts for Fourth Grade Primary Students
}

\author{
Dr. Alaa Shayal Fakhir Mohammed \\ Iraqi University - College of Arts - \\ Department of Translation \\ Iraq \\ bbnn801bn@gmail.com
}

\author{
Dr.Qasim Abdul Amir Hamidi \\ Karbala Education Directorate \\ Ministry of Education \\ Iraq \\ Bghdad2024@gmail.com
}

\begin{abstract}
The aim of the research is to identify the effect of the gradual erasure method in memorizing the literary texts for fourth-grade primary students. To achieve the research goal, the researcher used experimental design with two equal groups (experimental and control), as two divisions (A, B) were randomly chosen as a sample for research from fourth-grade primary students. In Al-Shaibani Primary School for Boys that were randomly chosen, the two groups were equal in variables (age in months, intelligence, students 'grades for the previous year) and t-test was calculated and the results were not statistically significant, the research sample consisted of (60) students, (30) students in The experimental group and (30) students in the control group. The students of the two groups studied the reading book (literary texts) for the fourth primary grade for eight weeks with two lessons per week. The students of the experimental group studied using the gradual erasure method and the students of the control group studied in the usual way. Literary texts, validation, reliability, and application were verified after the end of the experiment, and the SPSS statistical program was used to calculate t-test, paragraph difficulty factor, and the Alpha Cronbach coefficient. The results showed that there are statistically significant differences between the averages of the test scores in the reading subject among students of the experimental and control groups and in favor of students of the experimental group. In light of the results, the researcher concluded the effect of the gradual erasure method in memorizing the literary texts for fourth grade primary students, and he recommended several recommendations, including the use of the progressive erasure method in teaching and training teachers on their use.
\end{abstract}

Keywords: progressive erasure, memorization of literary texts, fourth elementary. 


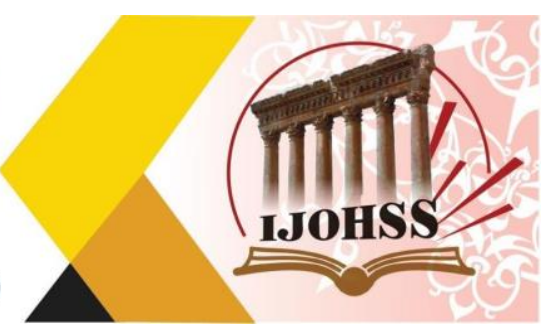

\section{الفصل الاول}

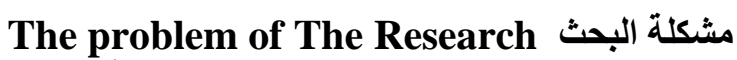

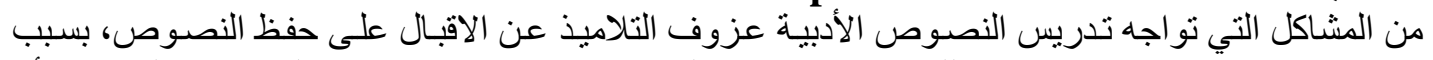

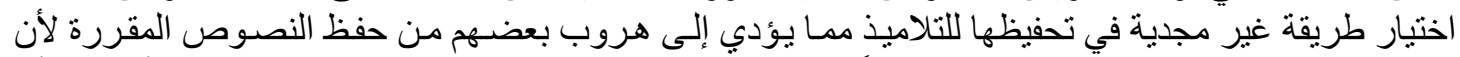

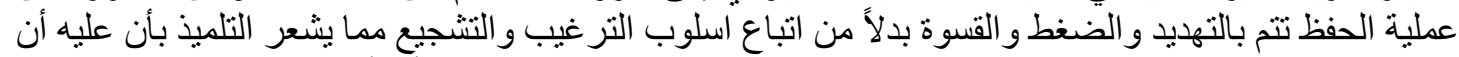

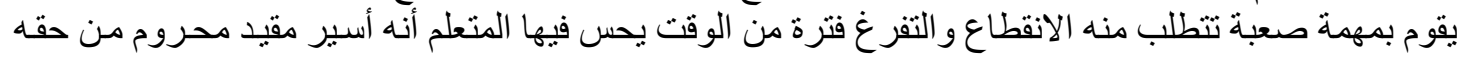
في الحرية. (احمد، 1983: 87)

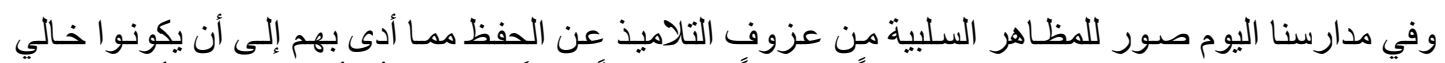



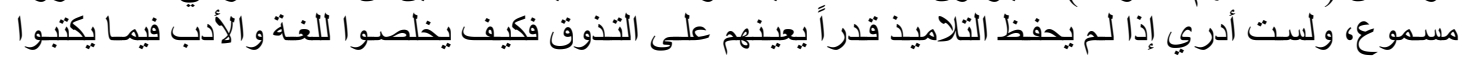
ويقولوا. (أحمد، 1983: 90)

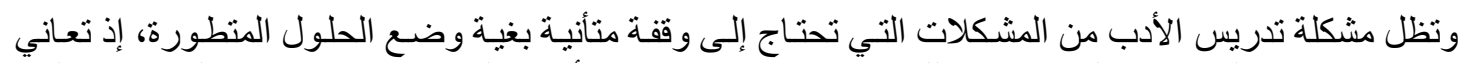

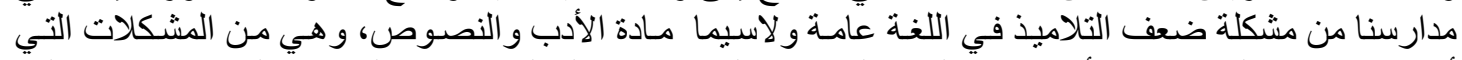

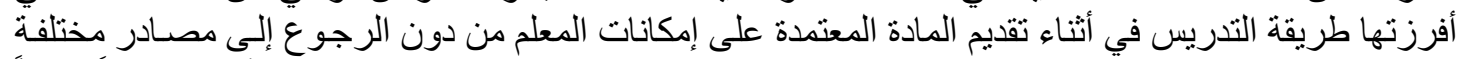

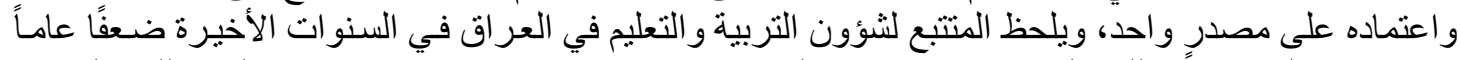

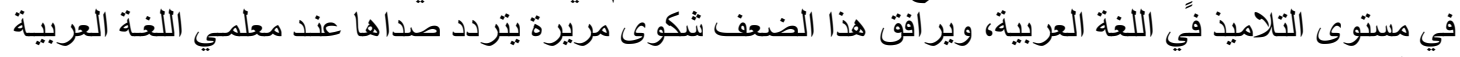
ومتطماتها. لذلك يمكن اجمال مشكلة البحث الحالي كالاتي : (اثر طريقة المحو التدريجي في حفظ النصوص الادبيـة لتلاميذ الصف الرئ الابع الابتدائي)

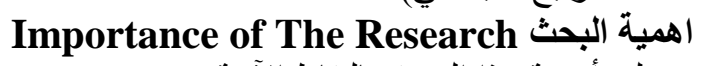
وتتجلى أهمية هذا البحث بالنقاط الآتية:

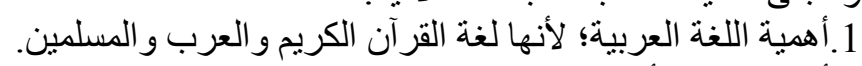



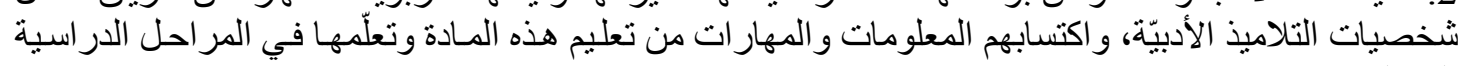
المختلفة. 3.أهميـة مـادة الأدب و النصـوص؛ لأنَّهـا تسـاعد التلاميذ على معرفـة مـآثر العرب وتـاريخهم الحافل بـالبطو لات

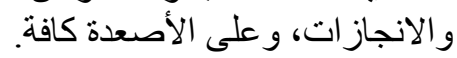

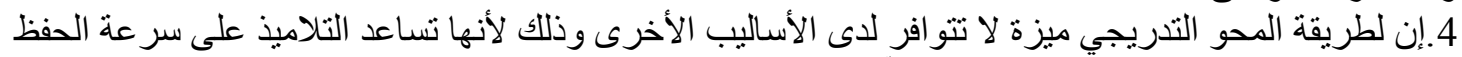

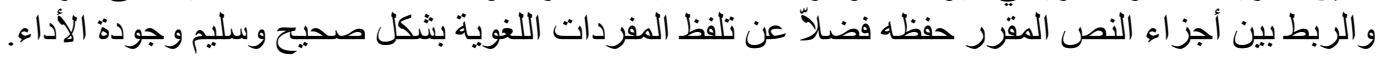

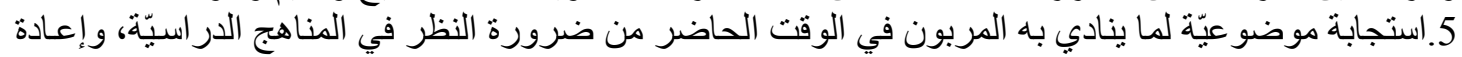

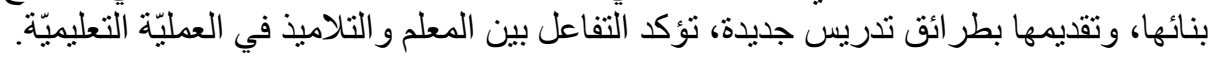

هاف البحث The aim of the Research يهدف البحث البى التعرف على اثر طريقة المحو التدريجي في حفظ النصوص الادبيـة لتلاميذ الصف الرابع الابتدائي .

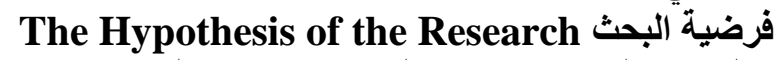
لغرض التحقق من هدف البحث تم صياغة الفرضية الاتية :

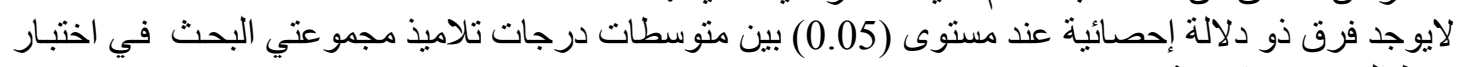
حفظ النصوص الادبية. 


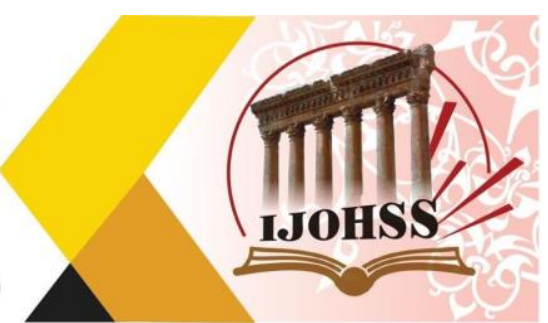

The Limitation of the Research حدود البحث

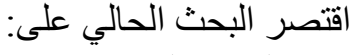

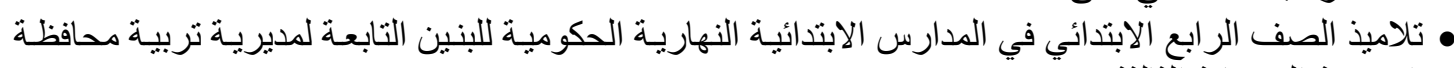
بغداد تربية الرصافة الثالثة.

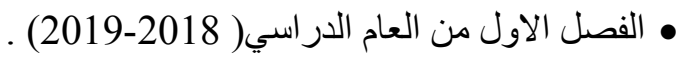

The Terms تحديد المصطلحات الاول الأن

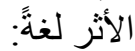

الأثر: بقية الثئُ ، و أثر في الثئ: ترك فيه أثر اً.(ابن منظور ، 1979: 19) الأثر اصطلاحاً عرفه:

1. (الحنفي ، 1991): بأنه " مقدار التغيُر الذي يطر أ على المتغِّر التابع بعد تعرضه لتأثير المتغير المستقل " (الحنفي ، 1991: 253)

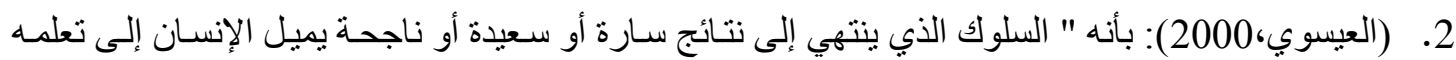

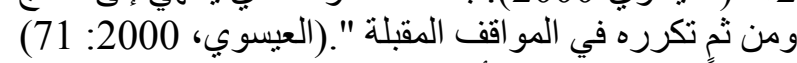
إجر ائياً: يعرفه الباحث بأنها: معرفة الأثرِ الذي تنركه (طريقة الذبانة المحو التدريجي) في حفظ النصوص الأدبية لتلاميذ الصف الر ابع الابتدائي.

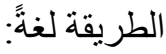



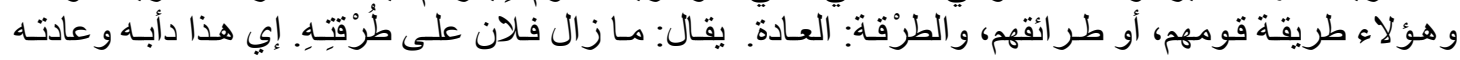

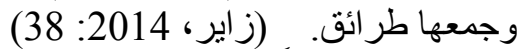
الطريقة اصطلاحاً عرفها:

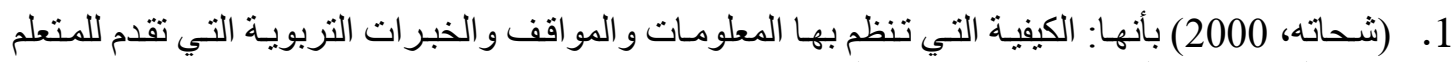

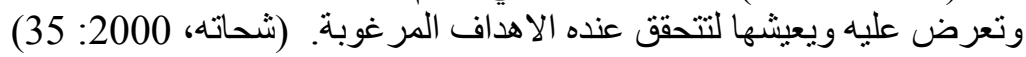

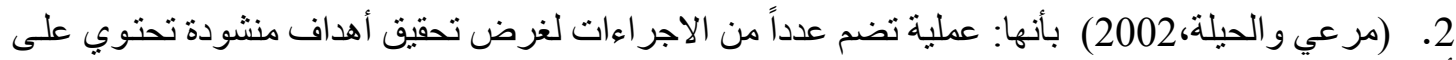

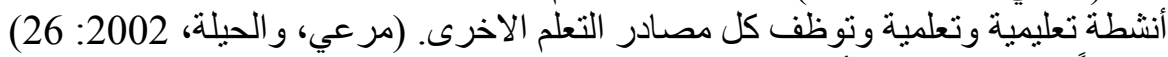
اجر ائياً: يعرفها الباحث بأنها:

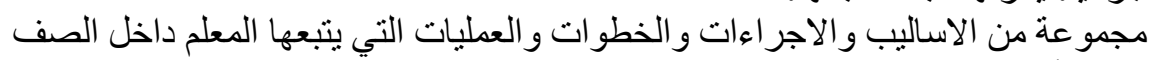
لتحقيق أهداف مر غوبة الاسبة

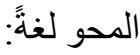

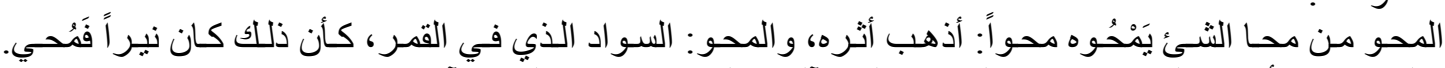

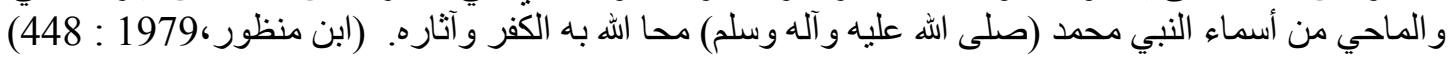
التدريج لغةً: دَرِجها إلىى كذا و استخدرجهُ، بمعنى: أدناه منهُ على التدريج.(ابن منظور، 1979: 963)

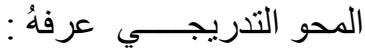

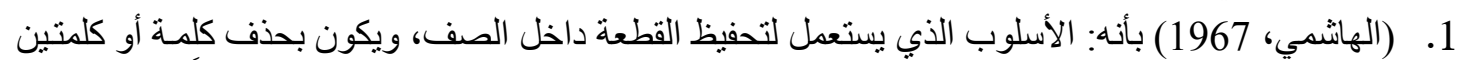

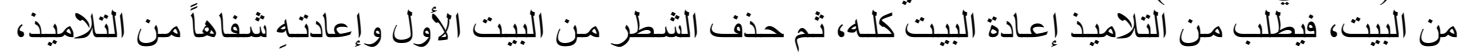
و هكذا.(الهاتشمي، 1967 : 1967

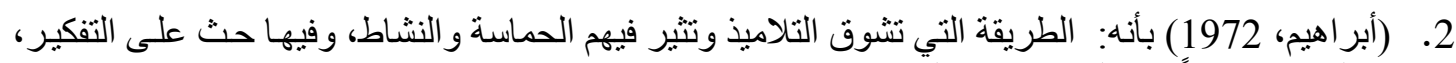

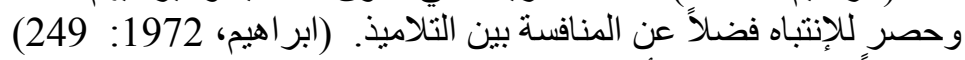

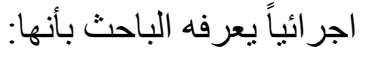




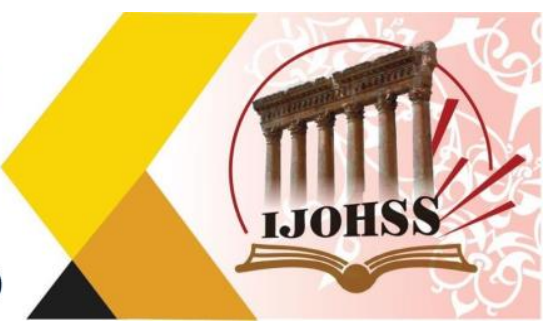

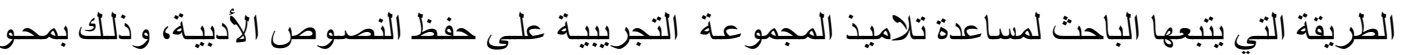

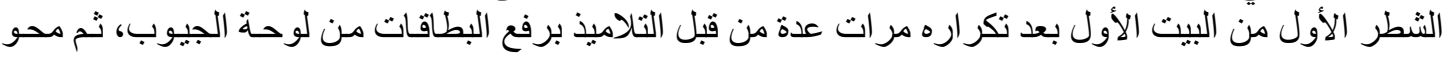

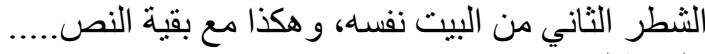

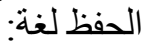

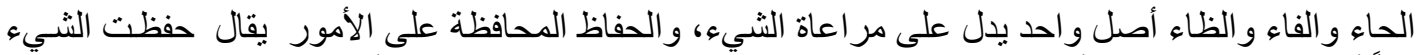

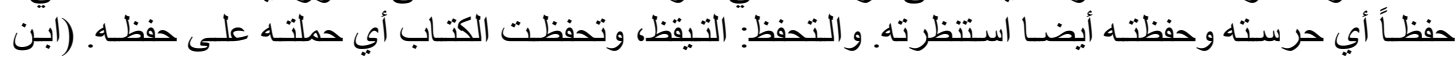
منظور، 2003: 200 حفظ (499)

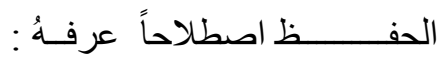

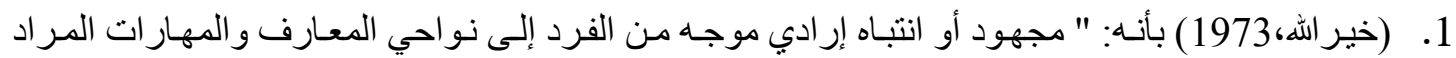

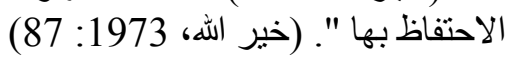

2. (راجح،1983) بأنه: قدرة الفرد على الاحتفاظ بما مر بـه من خبرات معرفية أو انفعالية. (راجح، 1983:

جر ائياً يعرفه الباحث بأنه:

قدرة تلاميذ مجمو عتي البحث (التجريبية و الضابطة) على الاحتفاظ بما اكتسبوه من معلومات لمدة معينة من

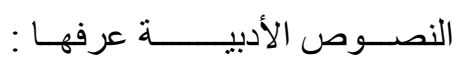

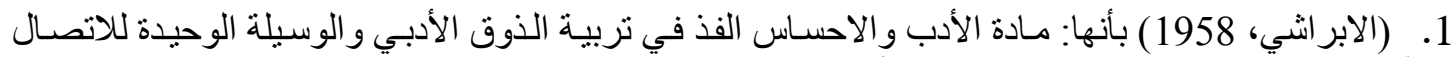



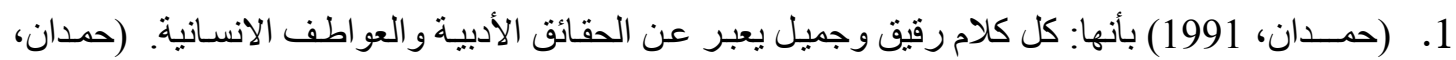

الجر ائياً يعرفها الباحث بأنها:

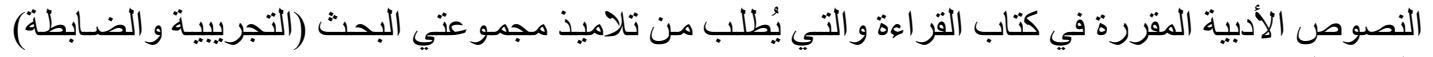

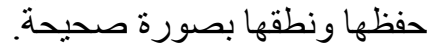

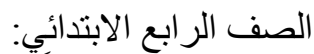

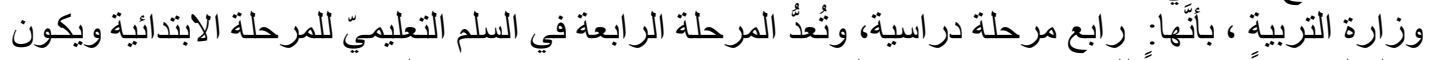

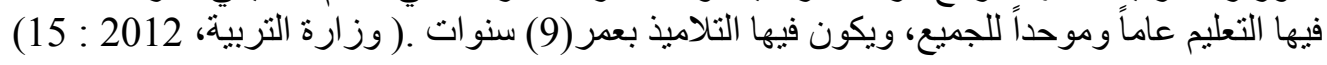

\section{الاطار النظري ودراستات سابقة الثاني}

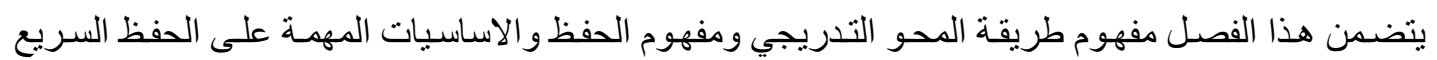

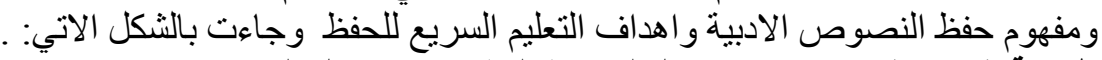

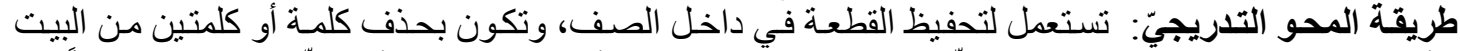

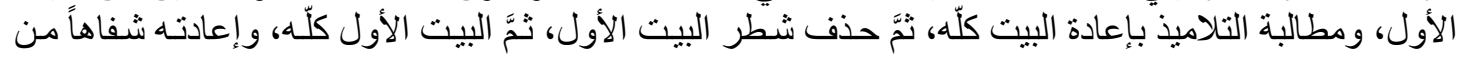
ومن محاسنها: أنَّ فيها حيويةً ونشاطاً وتنافساً شديداً بين التلاميذ، ويكون التلاميذ في شوق وترقب و اسع لمعرفة ما سيموه المدرس من أجزاء أنقاء القطعة.

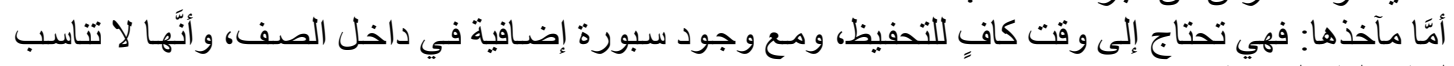

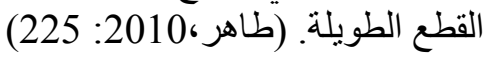




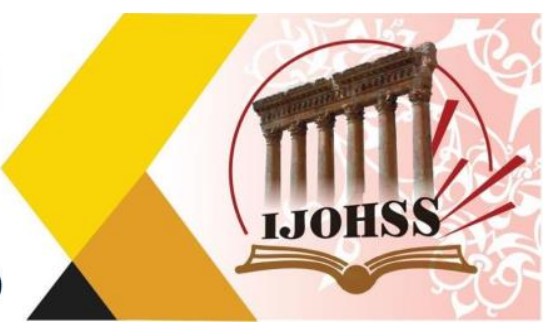

الحفظ

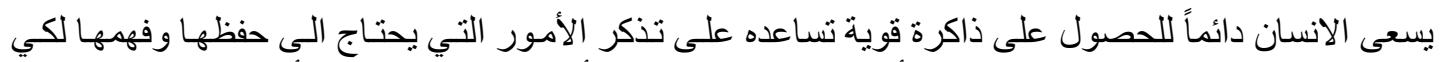

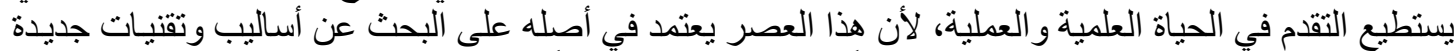



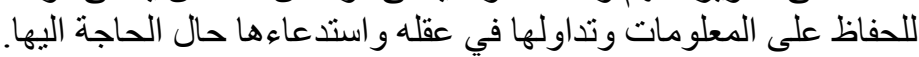

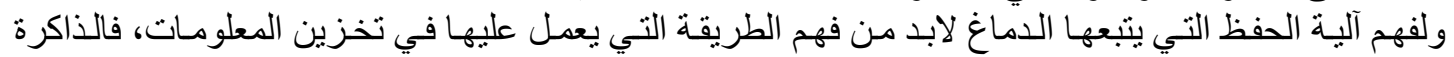

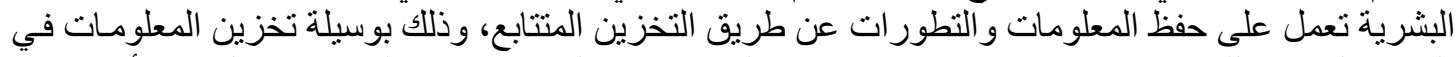

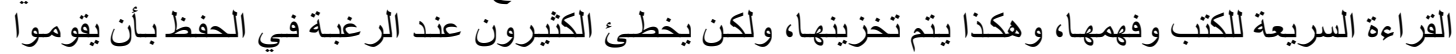

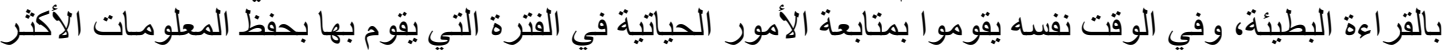

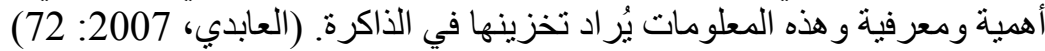

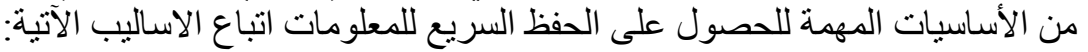

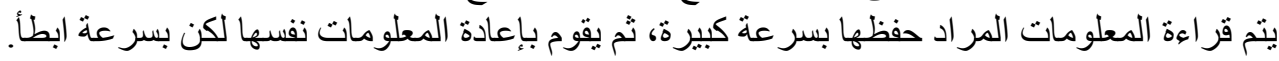

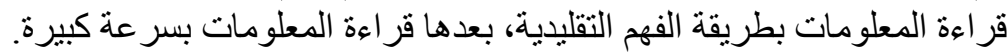

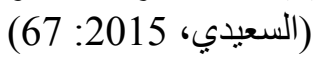

حفظ النصوص الأدبية

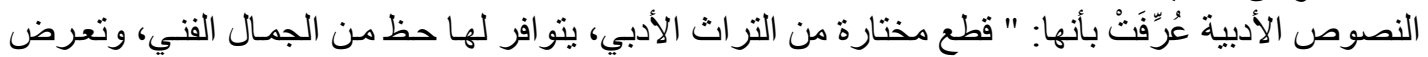

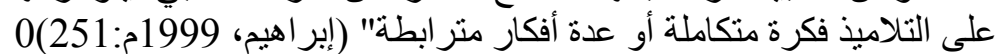

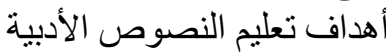



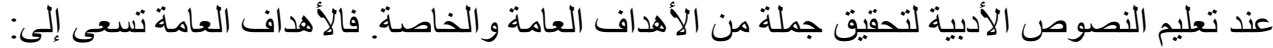

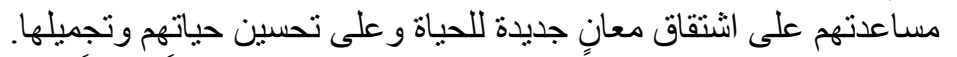

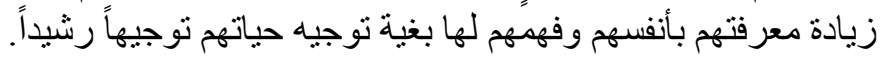

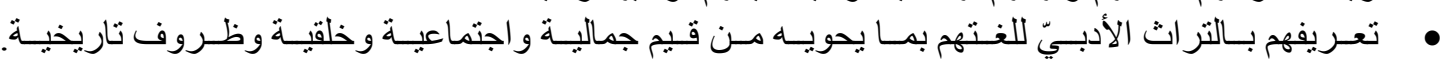

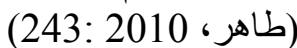
وأنَّ الحفظ يساعد على استقامة لغة التلميذ، وتصحيح لسانه وتربية ملكة الذوق الأدبيّ و لابدَّ أنْ يحفظ قدراً معيناً

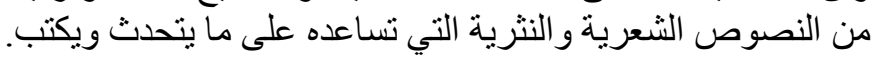

\section{الفصل الثالث}

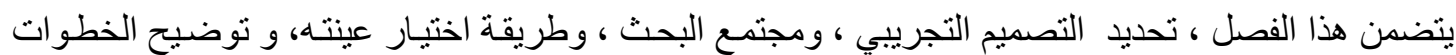

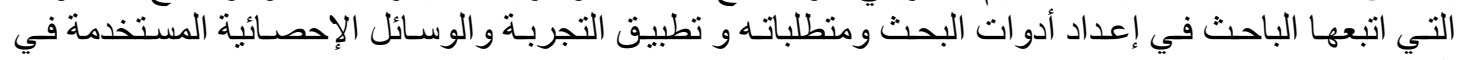

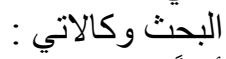

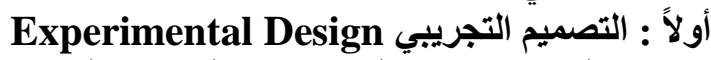

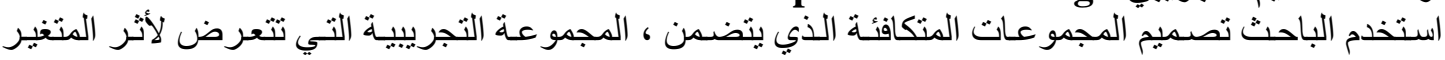

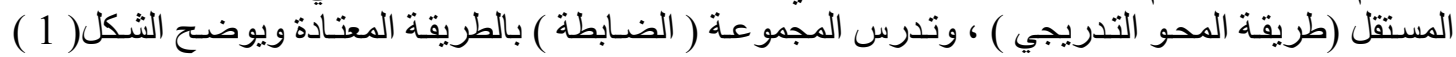
شكل (1) التصميم التجريبي للبحث التصميم التجريبي المستخدم في البحث .

\begin{tabular}{|c|c|c|c|}
\hline الأداة & المتغير التابع & المتغير المستقل & مجمو عات البحث \\
\hline \multirow[t]{2}{*}{ الادبية اختـار حفــ النصـوص } & \multirow{2}{*}{ 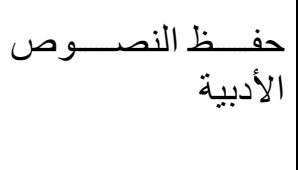 } & 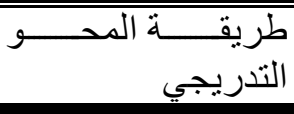 & التجريبية الاولى \\
\hline & & الطريقة التقليدية & \\
\hline
\end{tabular}




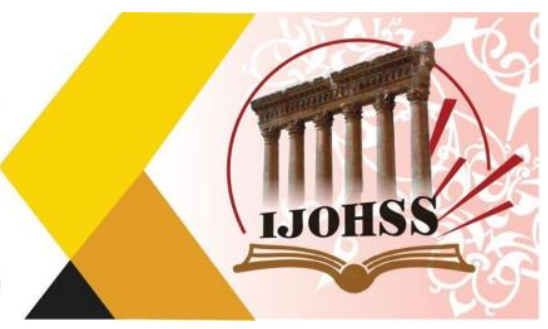

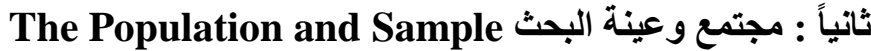

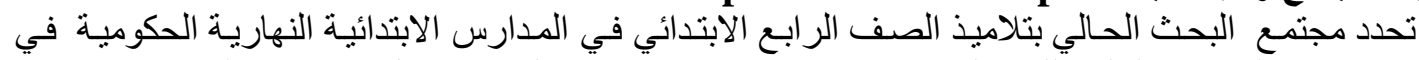

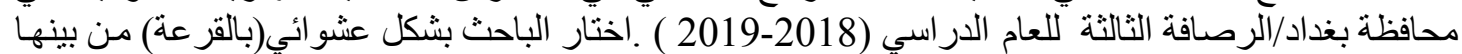

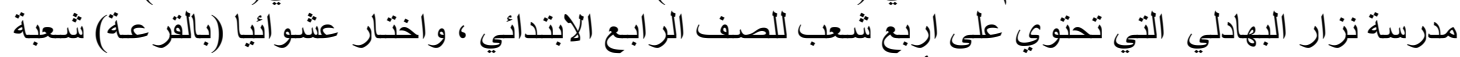

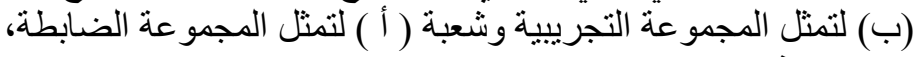

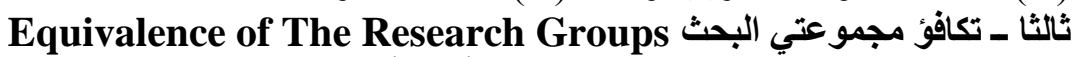
اختار الباحث مجمو عات البحث عثو البثن ائيا، وارتأى التأكد من تكافؤ ها إحصائيا من خلال المتغير ات الآتية :-

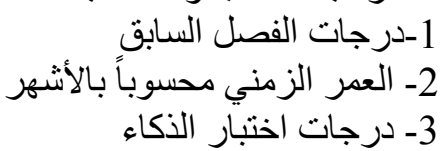

رابعاً: ضبط المتفيرات غير التخاء التجريبية ( الاخيلة)

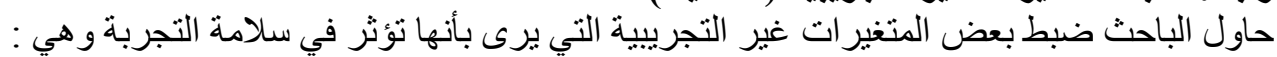

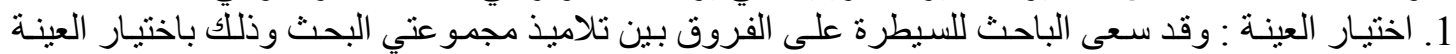

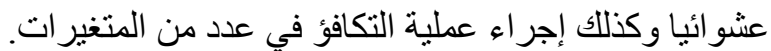

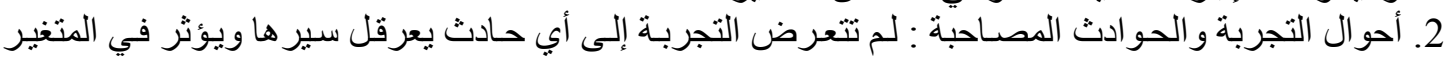

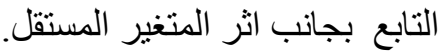
3. الاندثار التجريبي : لم ينتعرض البر البحث الحالي لمثل هذه الحالات ، باستثناء حالات الغياب الفردية التي تحدث في المدارس بشكل أعنبادي . 4.عامل النضج : لم يكن لهذارل العامل أثر في البحث الحالي ، لأن مدة التجربة كانت محدودة وموحدة للمجموعة التجريبية والضابطة.

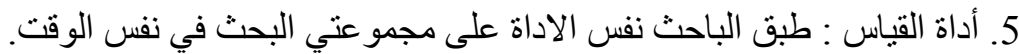

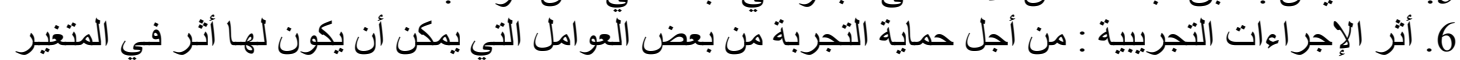

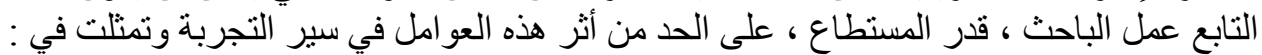

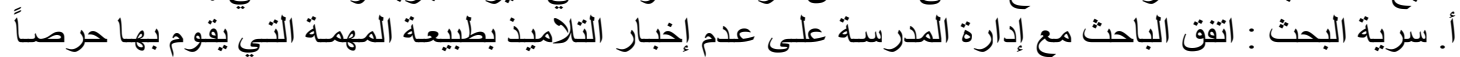

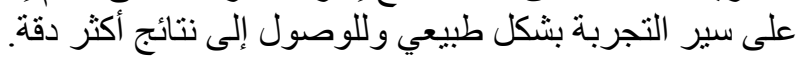

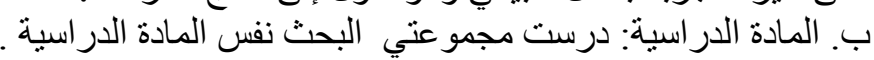

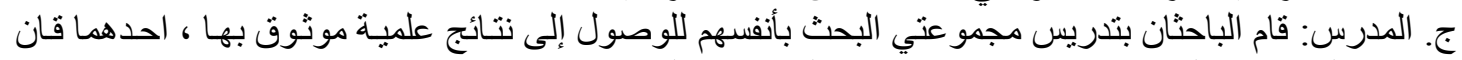

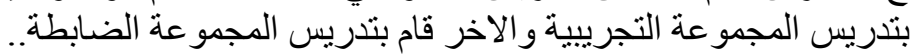

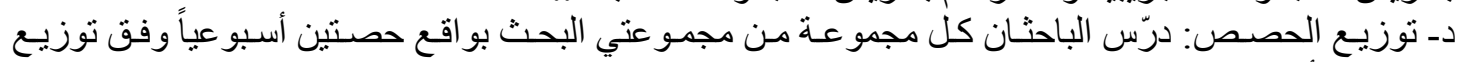

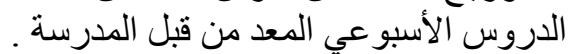

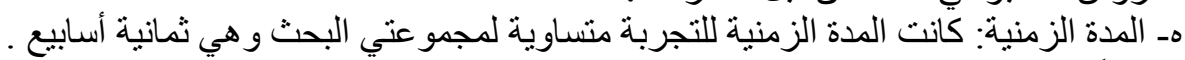


(1) تحديد المادة العلمبية

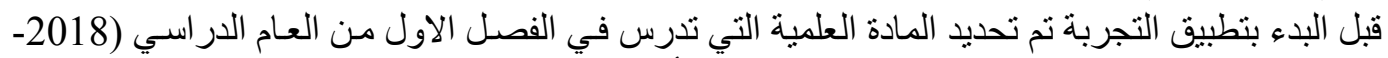

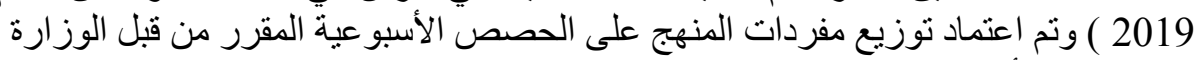

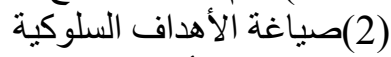

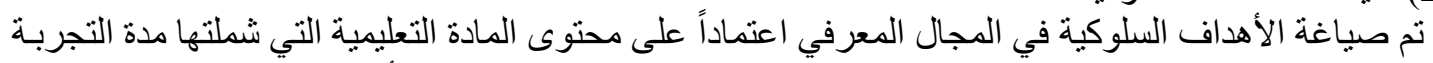

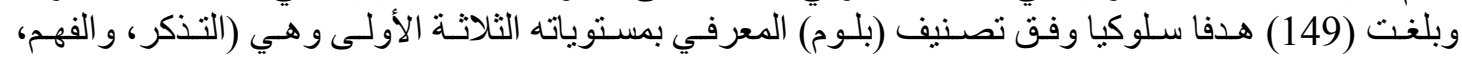

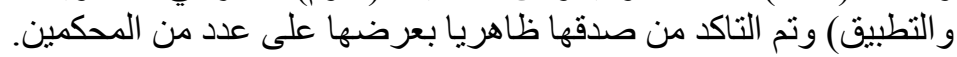

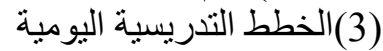

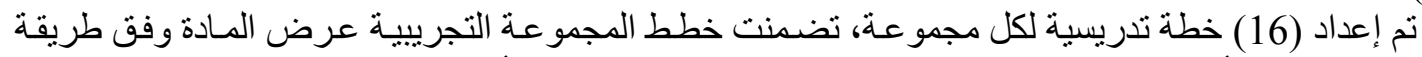
المحو التدريجي، أما الخطط التدريسية الخاصة بالمجمو عة الضابطة التي دُرِست وفق الطريقة الاعنيادية. 


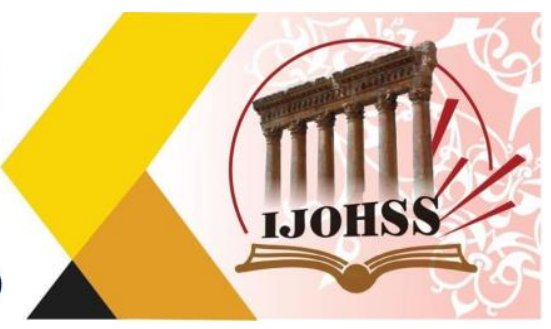

The Research Tool سادساً / أداة البحث

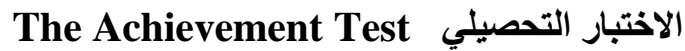

من أهداف هذا البحث قياس مستوى حفظ النصوص الأدبية لإى تلاميذ مجمو عتي البحث، وبعد اطلاع الباحث

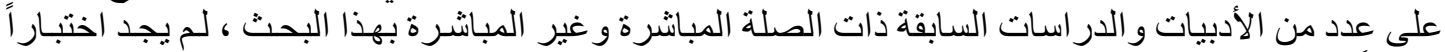

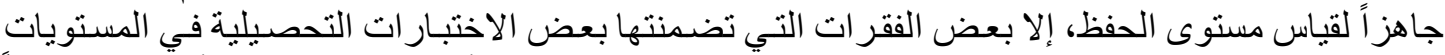

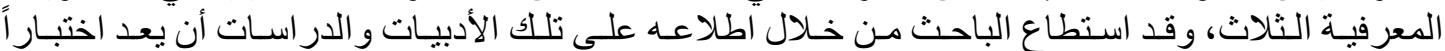

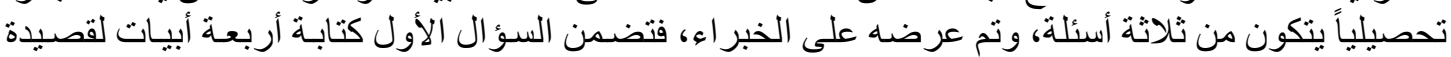

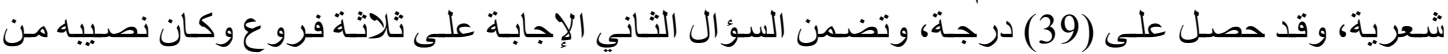

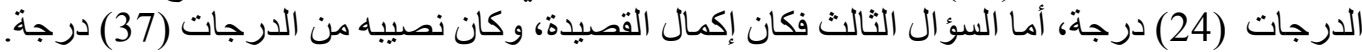
التطبيق الاستطلاعي للاختبار للتحقق من وضوح فقرات الاختبار وتعليمات الإجابة عنه و الوقت المستغرق في الإجابة، و التحليل الإحصائي



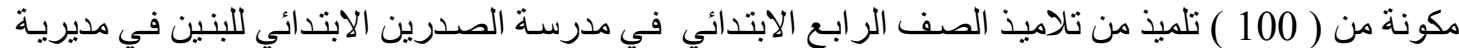

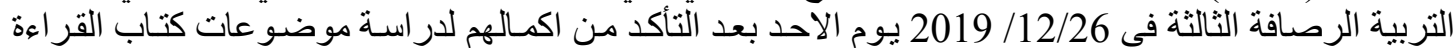

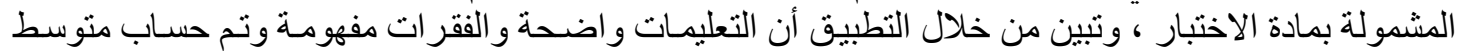

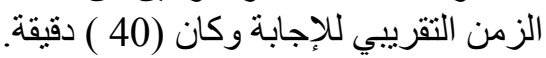
تحليل فقرات الاختبار إحصائيا

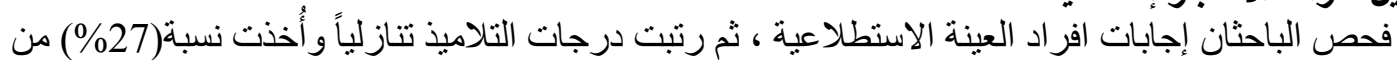

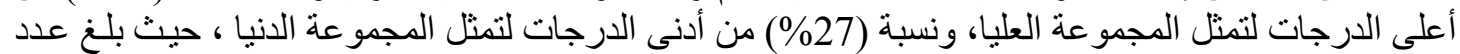

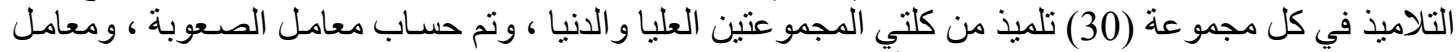
التمييز لكل فقرة من فقر ات الاختبار وكما يأتي :

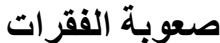

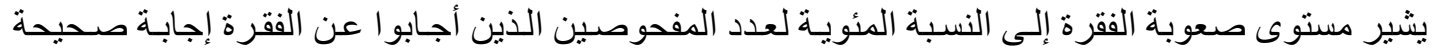

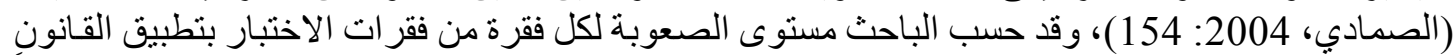

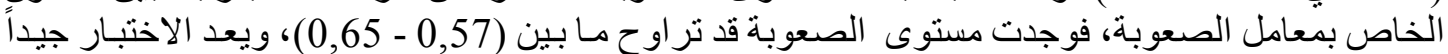



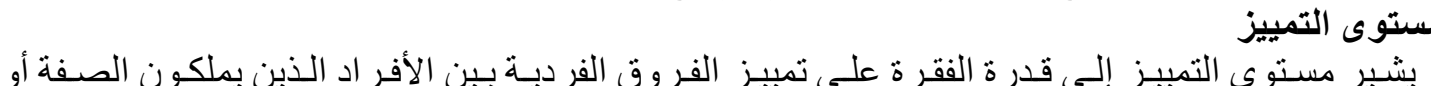



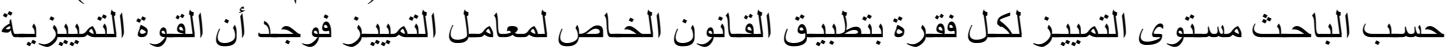

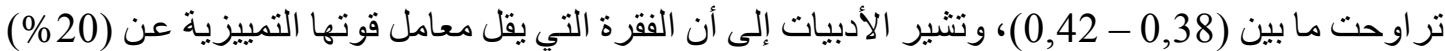
يستحسن حذفها أو تعديلها (امطانيوس،

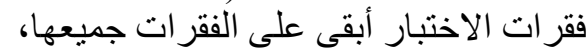
ثقبات الاختبار




للتطبيق على افر اد العينة.

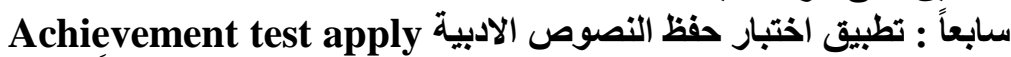

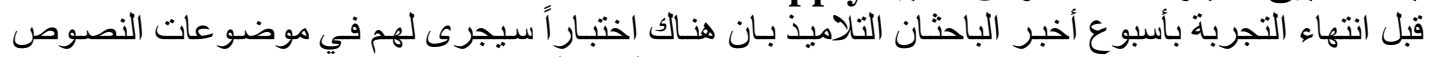

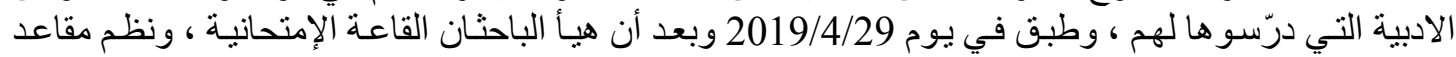

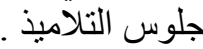
Statistical Treatment ثامناً : المعالجة الإحصائية استخدم الباحث البرنامج الإحصائي SPSS لحساب :النسبة المئوية 

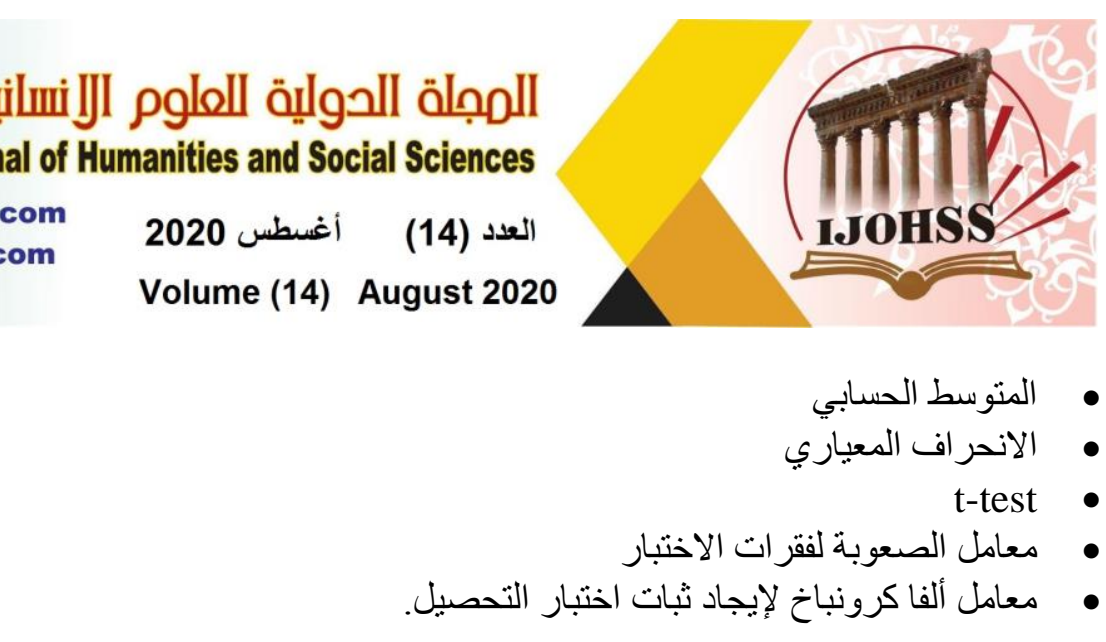

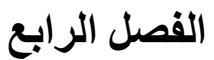 \\ عرض النتائج وتفسير الراعها}

يتضمن هذا الفصل عرض النتائج وتفسير ها والاستنتاجات و التوصيات و المقترحات . عرض النتائج

للتحقق من الفرضية الصفرية للبحث (لا توجد فروق ذات دلالة إحصائية عند مستوى (0.05) بين متوسطات

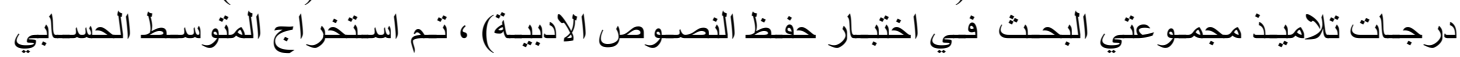



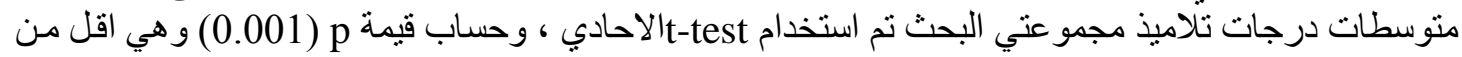

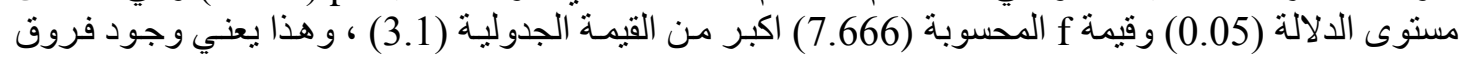

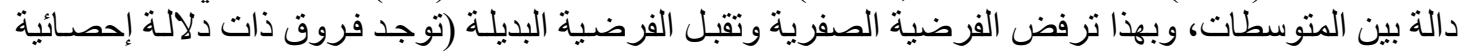
عند مستوى (0.05) بين منوسطات درجات تلاميذ مجمو عتي البحث في اختبار حفظ النصوص النئ الادبية تفسير النتائت ومناقثتنها أسفرت النتائج عن الآتي:

تفوق تلاميذ الرجمو عالقة التجريبية الذين درسوا باستخدام طريقة المحو التدريجي على اقر انهم في المجمو عـة

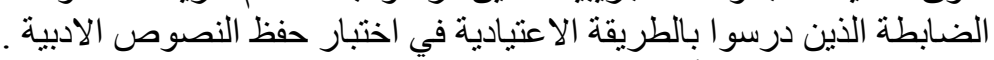

ويعزو الباحثان ذلك للأسباب الآتية:

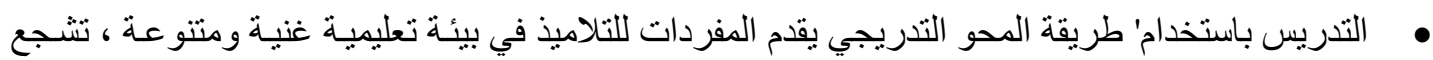
على الحفظ بصورة بسيطة ، ودفعهم إلى تحقيق الاهداف التعليمية المنشودة.

• • يتيح التدريس باستخدام طريقة المحو التنديجي الفرصة للتلاميذ لعرض مفردات المسادة الدراسية بطريقة تختلف عن النمط التقليدي في التنريس و الحفظ. • بضيف التدريس باستخدام طريقة المحو التدريجي قدرا من التشويق والحرية للتلميذ ويقلل من الملل

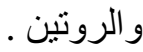
• أثر (طريقة المحو التدريجي) في تطوير قدرة الثنلاميذ على استرّرجاع المفردات النتي درسوها بسهولة

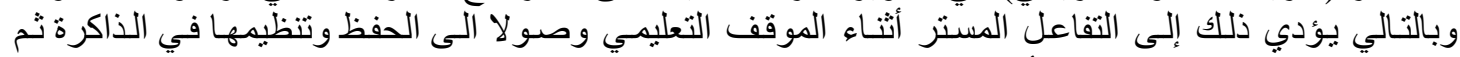
استرجأعها و وجعل عملية التعلم أكثر فاعلية. • • (طريقة المحو التدريجي) تعطي الفرصة للتلاميذ للتفاعل المستمر وزيادة قدرته على الحفظ وجعل إمكانية

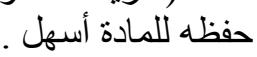

Conclusions الاستنتاجات

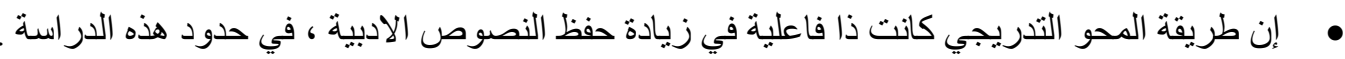

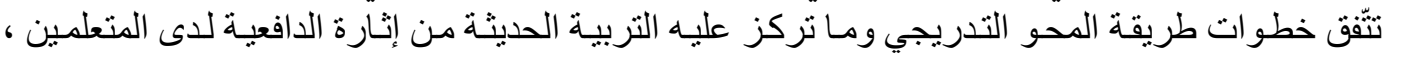
وزيادة نشاطهم ، وفاعليتهم ، ومر اعاة الفروق الفردية بينهم

Recommendations التوصيات • اعتماد طريقة المحو التدريجي في تدريس مادة الأدب و النصوص التلاميذ الصف الرابع الابتدائي ومر احل 
المجلة اللدولية اللملوم الأسانية والإجتاعياة

International Journal of Humanities and Social Sciences

website:www.ijohss.com

Email:editor@ijohss.com

أغسطس 2020

العدد (14)

ISSN: $2415-4822$

Volume (14) August 2020

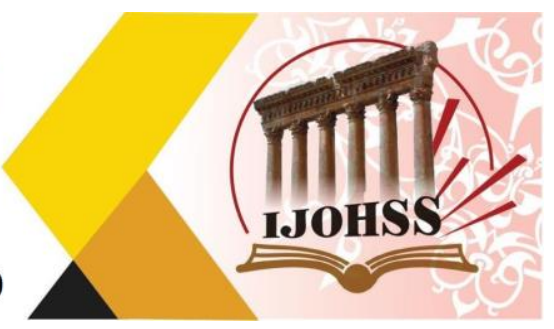

• تدريب معلمي ومدرسي مادة اللغة العربية على طريقة المحو التدريجي من خلال إعدادهم في الكليات أو

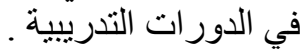
• تو توجيه المعلمين و المدرسين إلى عدم الاقتصار على الأساليب التقليدية ، وضرورة تلتويع استعمال الأسـاليب

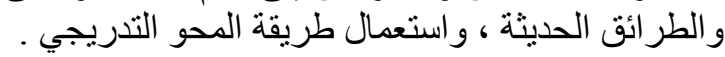

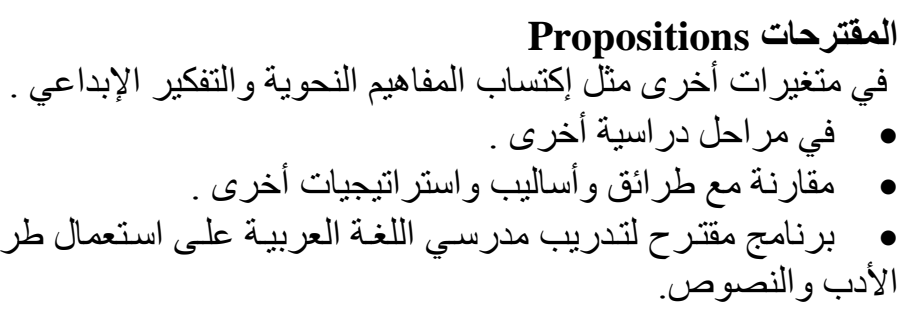

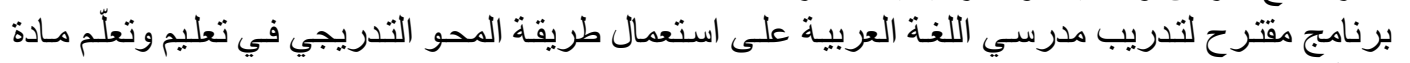

1. الابر اثشي، محمد عطية. الطرق الخاصة في التربية لتدريس اللغة العربية والدين، ط2، مطبعة الإرشاد،

2.

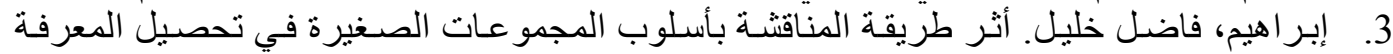

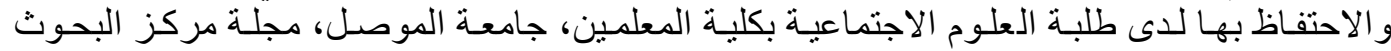

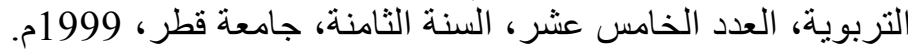

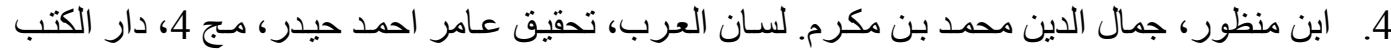

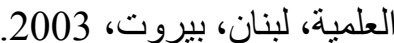

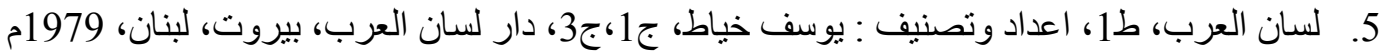

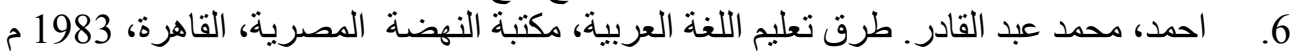

7. 8.

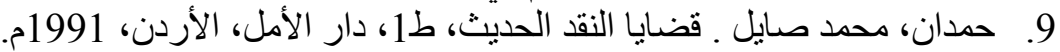

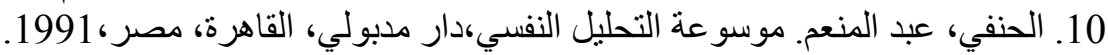

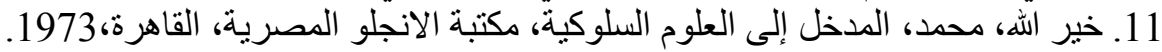

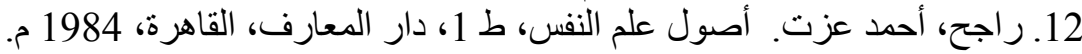

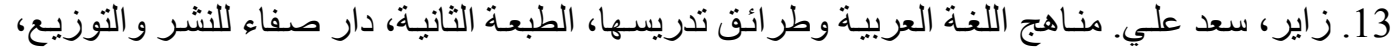

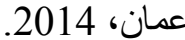

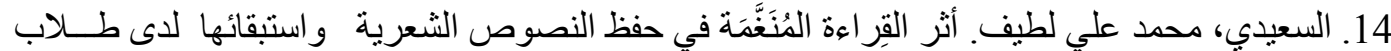

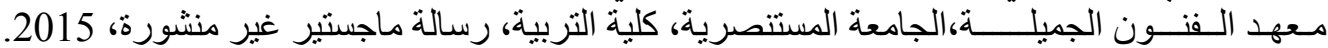



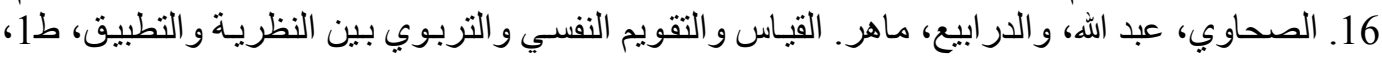

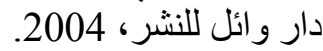
17. طاهر، علوي عبد الله ـ تدريس اللغة العربية وفقاً لاحدث الطر ائق التربويـةطأ1 دار المسيرة، الاردن، .2010

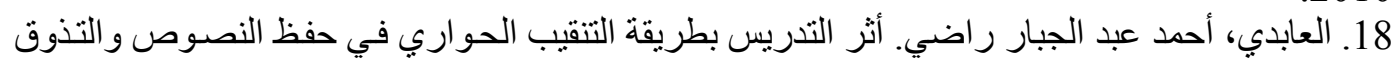

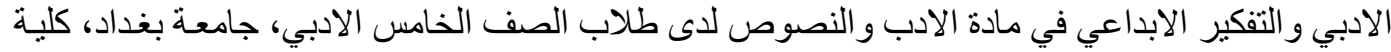
التربية، ابن رشد،( اطروحة دكتور اه غير منشورة )، 2007. 


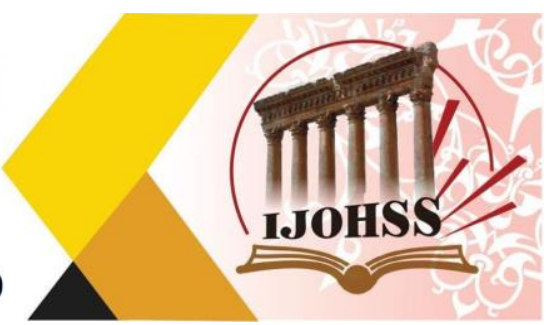

ISSN: $2415-\mathbf{4 8 2 2}$

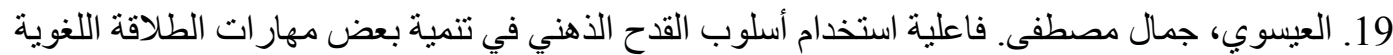
و علاج الأخطاء الاملائية لاى تلميذات الحلقة الثانية بدولة الإمارات، مجلة كلية التربيـة، جامعـة الإمـار اته،

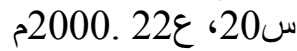
20. فرج، صفوت. القياس النفسي، القاهرة، دار النهضة العربية، 1980.

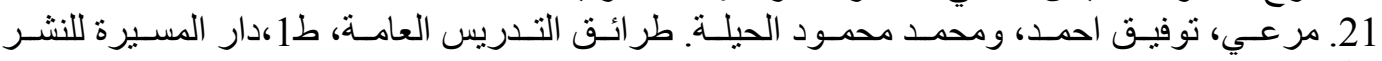

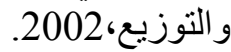

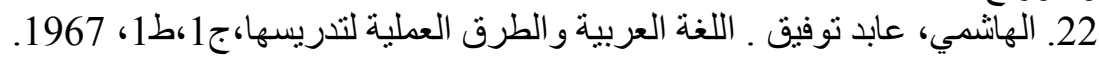

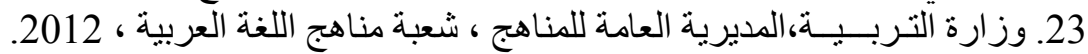

\section{References}

1. Al-Ibrashi, Mohamed Attia. Special Methods of Education for Teaching Arabic Language and Religion, 2nd Edition, Al-Irshad Press, Baghdad, 1958.

2. Ibrahim, Abdel-Alim. The Technical Instructor for Arabic Language Teachers, 6th Edition, Dar Al-Maarif, Egypt, 1972

3. Ibrahim, Fadel Khalil. The effect of the method of discussion in the method of small groups in obtaining and retaining knowledge among students of social sciences, Teachers College, University of Mosul, Journal of Educational Research Center, the fifteenth issue, eighth year, Qatar University, 1999 AD.

4. Ibn Manzoor, Jamal Al-Din Muhammad bin Makram. Lisan Al-Arab, Aamir Ahmed Haider Inquiry, Volume 4, Dar Al-Kutub Al-Alami, Lebanon, Beirut, 2003.

5. Ahmed, Muhammad Abdul Qadir. Methods of Teaching Arabic Language, The Egyptian Renaissance Library, Cairo, 1983

6. Imam, Mustafa Mahmoud and others, Calendar and Measurement, Dar Al-Hekma for Printing and Publishing, Baghdad, 1990.

7. Matanius, Michael. Measurement and Evaluation in Modern Education, Damascus University Publications, Syria, 1997.

8. Lisan Al-Arab, First Edition, Prepared and Classified: Youssef Khayyat, Part 1, Part 3, Dar Lisan Al-Arab, Beirut, Lebanon, 1979 AD

9. Hamdan, Muhammad Sayel . Issues of Modern Criticism, 1st Edition, Dar AlAmal, Jordan, 1991.

10. Al-Hanafi, Abdel-Moneim. Encyclopedia of Psychoanalysis, Dar Madbouly, Cairo, Egypt, 1991.

11. Khairallah, Muhammad, Introduction to Behavioral Sciences, The Egyptian Anglo Library, Cairo, 1973.

12. Rajeh, Ahmed Ezzat. Fundamentals of Psychology, 1st edition, Dar Al-Maarif, Cairo, 1984.

13. Zayer, Saad Ali. Arabic Language Curricula and Teaching Methods, Second Edition, Dar Safa for Publishing and Distribution, Amman, 2014.

14. Al-Saeedi, Muhammad Ali Latif. The effect of toned reading on preserving and retaining poetic texts among students of the Fine Art Institute, Al-Mustansiriya University, College of Education, unpublished Master Thesis, 2015.

15. Shehata, Hassan. Teaching the Arabic language between theory and practice, 4th edition, Egyptian Lebanese House, Egypt, 2000 AD. 
16. Al-Sahwi, Abdullah, Al-Daraabi, Maher. Psychological and educational evaluation and evaluation between theory and practice, 1st edition, Wael Publishing House, 2004.

17. Taher, Alawi Abdullah. Teaching Arabic according to the latest educational methods, 1st edition, Al Masirah House, Jordan, 2010.

18. Al-Abdi, Ahmed Abdul-Jabbar Radhi. The Impact of Teaching in a Dialogic Exploration Method on Memorizing Texts, Literary Appreciation, and Creative Thinking in Literature and Texts for Fifth Literary Class Students, University of Baghdad, College of Education, Ibn Rushd, (unpublished doctoral thesis), 2007.

19. El-Essawy, Gamal Mostafa. The effectiveness of using the method of mental libido in developing some language fluency skills and treating spelling errors among students of the second cycle in the Emirates, Journal of the College of Education, Emirates University, Q 20, p. 22, 2000 AD

20. Faraj, Safwat. Psychometrics, Cairo, Arab Renaissance House, 1980.

21. Mari, Tawfiq Ahmed, and Mohamed Mahmoud Al-Hilla. General Teaching Methods, 1st Edition, Al Masirah House for Publishing and Distribution, 2002.

22. Al-Hashemi, Abed Tawfiq. Arabic Language and Practical Methods for Teaching It, Part 1, 1st Edition, 1967.

23. Ministry of Education, General Directorate of Curricula, Arabic Curricula Division, 2012. 